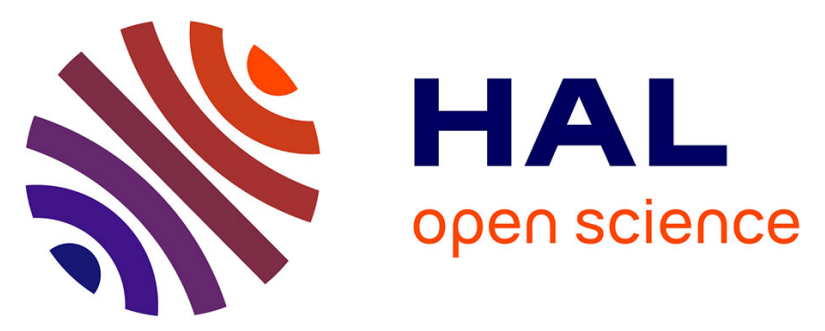

\title{
Venoarterial extracorporeal membrane oxygenation for refractory cardiogenic shock post-cardiac arrest
}

Marc Pineton de Chambrun, Nicolas Bréchot, Guillaume Lebreton, Matthieu

Schmidt, Guillaume Hekimian, Pierre Demondion, Jean Trouillet, Pascal

Leprince, Jean Chastre, Alain Combes, et al.

\section{To cite this version:}

Marc Pineton de Chambrun, Nicolas Bréchot, Guillaume Lebreton, Matthieu Schmidt, Guillaume Hekimian, et al.. Venoarterial extracorporeal membrane oxygenation for refractory cardiogenic shock post-cardiac arrest. Intensive Care Medicine, 2016, 10.1007/s00134-016-4541-y . hal-01393802

\section{HAL Id: hal-01393802 \\ https://hal.sorbonne-universite.fr/hal-01393802}

Submitted on 8 Nov 2016

HAL is a multi-disciplinary open access archive for the deposit and dissemination of scientific research documents, whether they are published or not. The documents may come from teaching and research institutions in France or abroad, or from public or private research centers.
L'archive ouverte pluridisciplinaire HAL, est destinée au dépôt et à la diffusion de documents scientifiques de niveau recherche, publiés ou non, émanant des établissements d'enseignement et de recherche français ou étrangers, des laboratoires publics ou privés. 
1 Venoarterial-Extracorporeal Membrane Oxygenation for Refractory Cardiogenic Shock

2 Post-Cardiac Arrest

4 Marc Pineton de Chambrun ${ }^{1}$, Nicolas Bréchot ${ }^{1}$, Guillaume Lebreton ${ }^{2}$, Matthieu Schmidt ${ }^{1}$,

5 Guillaume Hekimian ${ }^{1}$, Pierre Demondion ${ }^{2}$, Jean-Louis Trouillet ${ }^{1}$, Pascal Leprince ${ }^{2}$, Jean

6 Chastre $^{1}$, Alain Combes ${ }^{1}$, Charles-Edouard Luyt ${ }^{1 *}$

$7 \quad{ }^{1}$ Service de Réanimation Médicale, Groupe Hospitalier La Pitié-Salpêtrière, Assistance

8 Publique-Hôpitaux de Paris, Paris, France. Sorbonne Universités, UPMC Université Paris 06,

9 INSERM, UMRS_1166-ICAN Institute of Cardiometabolism and Nutrition, Paris, France.

$10{ }^{2}$ Service de Chirurgie Thoracique et Cardiovasculaire, Groupe Hospitalier La Pitié-Salpêtrière,

11 Assistance Publique Hôpitaux de Paris, Paris, France.

12 Short Title: VA-ECMO for Cardiogenic Shock Post-Cardiac Arrest

13 *Correspondence: Charles-Edouard Luyt, MD, PhD, Service de Réanimation Médicale, iCAN,

14 Groupe Hospitalier La Pitié-Salpêtrière, 47-83, boulevard de l'Hôpital, 75651 Paris Cedex 13,

15 France. tel: +33 (0)1 421638 24; fax: +33 (0)1 421638 17; email: charles-

16 edouard.luyt@aphp.fr

17 Total word count: 3003 words.

\section{Conflicts of Interest}

19 Dr Combes is the primary investigator of the EOLIA trial (NCT01470703), a randomized trial of

20 VV-ECMO, supported in part by MAQUET. Drs Bréchot, Lebreton and Combes have received

21 honoraria for lectures by MAQUET. The other authors declare that they have no conflicts of

22 interest related to the purpose of this manuscript. 
1 Abstract: Word count: 245

2 Purpose: To describe the characteristics, outcomes and risk factors associated with poor outcome

3 of venoarterial-extracorporeal membrane oxygenation (VA-ECMO)-treated patients with

4 refractory shock post-cardiac arrest.

5 Methods: We retrospectively analyzed data collected prospectively (March 2007- January 2015)

6 in a 26-bed tertiary hospital intensive care unit. All patients implanted with VA-ECMO for

7 refractory cardiogenic shock after successful resuscitation from cardiac arrest were included.

8 Refractory cardiac arrest patients, given VA-ECMO under cardiopulmonary resuscitation, were

9 excluded.

10 Results: Ninety-four patients received VA-ECMO for refractory shock post-cardiac arrest. Their

11 hospital and 12-month survival rates were $28 \%$ and $27 \%$, respectively. All 1-year survivors were

12 cerebral performance category 1 . Multivariable analysis retained INR $>2.4$ (OR 4.9; $95 \%$ CI

13 1.4-17.2), admission SOFA score >14 (OR 5.3; 95\% CI 1.7-16.5) and shockable rhythm (OR

$14 \quad 0.3 ; 95 \%$ CI $0.1-0.9$ ) as independent predictors of hospital mortality, but not SAPS II, out-of-

15 hospital cardiac arrest score or other cardiac arrest variables. Only $10 \%$ of patients with an

16 admission SOFA score $>14$ survived, whereas $50 \%$ of those with scores $\leq 14$ were alive at 1 year.

17 Restricting the analysis to the 67 patients with out-of-hospital cardiac arrest of coronary cause

18 yielded similar results.

19 Conclusion: Among 94 patients implanted with VA-ECMO for refractory cardiogenic shock

20 post-cardiac arrest resuscitation, the 24 (27\%) 1-year survivors had good neurological outcomes,

21 but survival was significantly better for patients with admission SOFA scores <14, shockable

22 rhythm and INR $\leq 2.4$. VA-ECMO might be considered a rescue therapy for patients with

23 refractory cardiogenic shock post-cardiac arrest resuscitation. 
ICME-D16-00906 R5

2 Keywords: Cardiac arrest - Cardiogenic shock $\cdot$ Extracorporeal membrane oxygenation $\cdot$ Post-

3 cardiac arrest syndrome

4

5 Take-home message: Refractory cardiogenic shock is one of the leading causes of early death

6 after successful cardiac arrest resuscitation. In this setting, venoarterial-extracorporeal membrane

7 oxygenation is associated with $27 \%$ 1-year survival. Patients with SOFA scores $>14$ have poorer

8 outcomes than the others (respective survival 10\% vs. 50\%), raising the question of futility in

9 these patients.

10 


\section{Introduction}

2 Hospital mortality of patients post-cardiac arrest resuscitation remains particularly high, ranging

3 from $40 \%$ to $90 \%$ [1-9]. The main causes of death are multiorgan failure within the first hours

4 following the return of spontaneous circulation and neurological damage (mainly anoxic cerebral

5 lesions) several days later [10]. Early multiorgan failure may result from post-cardiac arrest

6 syndrome or myocardial disease-related cardiogenic shock that led to cardiac arrest. Post-cardiac

7 arrest syndrome exhibits a set of relatively stereotypical events, among which cardiocirculatory

8 failure usually dominates the clinical picture and often leads to multiorgan failure. Post-cardiac

9 arrest syndrome usually combines cardiogenic and vasodilatory components: left ventricular

10 dysfunction begins early, within minutes after the return of spontaneous circulation and can be

11 secondarily associated with severe vasodilatation, attributable to a generalized inflammatory

12 syndrome, or myogenic and/or metabolic autoregulation [11-14]; it spontaneously reverses after

13 several hours, but can sometimes be very severe, leading to multiorgan failure and death.

14 However, cardiogenic shock may also occur without that syndrome, depending on cardiac disease

15 origin (ischemic disease, drug overdose...).

Venoarterial-extracorporeal membrane oxygenation (VA-ECMO) is an effective

17 technique to rescue patients with refractory cardiogenic shock [15-17]. In the setting of cardiac arrest, many studies focusing on VA-ECMO's role in extracorporeal cardiopulmonary

19 resuscitation (e-CPR) for refractory cardiac arrest yielded conflicting results [18-20]. However,

20 VA-ECMO usefulness in patients with refractory cardiogenic shock post-cardiac arrest has not

21 yet been reported. Using such an invasive and expensive technique in this context is debatable

22 because the neurological prognosis at the time of implantation is unknown. Therefore, we

23 undertook this retrospective analysis of patients treated with VA-ECMO for refractory 
1 cardiogenic shock post-cardiac arrest to describe their characteristics, outcomes and risk factors

2 associated with poor outcome.

\section{Methods}

\section{Patients}

6 We retrospectively reviewed the prospectively constituted ECMO database of our 26-bed

7 intensive care unit (ICU) to identify patients who received (March 2007-January 2015) VA-

8 ECMO for refractory cardiogenic shock post-cardiac arrest resuscitation. Before VA-ECMO

9 implantation, every patient underwent Doppler echocardiography to evaluate cardiac and

10 hemodynamic status. In our unit and for this study, VA-ECMO for acute-refractory cardiogenic

11 shock is usually indicated when the following criteria are met: persistence or aggravation of

12 tissue hypoxia (extensive skin mottling, anuria, neurological impairment, elevated blood

13 lactate...) despite adequate fluid loading; severely depressed left ventricle ejection fraction

$14(<25 \%)$ with low cardiac output (defined as aortic velocity-time integral $<8 \mathrm{~cm}$ and sustained

15 hypotension despite infusion of very high-dose catecholamines (epinephrine $>1 \mu \mathrm{g} / \mathrm{kg} / \mathrm{min}$ or

16 dobutamine $>20 \mu \mathrm{g} / \mathrm{kg} / \mathrm{min}$ with norepinephrine $>1 \mu \mathrm{g} / \mathrm{kg} / \mathrm{min}$ ). However, because most ECMO

17 systems were implanted in other hospitals, it was impossible to precisely verify that all patients

18 satisfied all these criteria. Patients implanted with VA-ECMO for refractory cardiac arrest under

19 CPR were excluded from this study.

\section{ECMO implantation}

22 The detailed surgical procedure for femoral-femoral VA-ECMO placement was described

23 previously $[16,17,21]$. Briefly, trained cardiovascular surgeons performed all procedures at the 
1 bedside or in the cardiac angiography room because of patient's hemodynamic instability.

2 Femoral vessels were cannulated after limited cut-down using the Seldinger technique and an

3 additional 7F catheter was systematically inserted distally into the femoral artery to prevent

4 severe leg ischemia. For highly unstable patients diagnosed with refractory cardiogenic shock in

5 other hospitals, our institution's Mobile Circulatory Assistance Unit traveled rapidly to primary-

6 care hospitals with a portable ECMO system, installed the device before refractory multiorgan

7 failure or cardiac arrest took hold, and then transported the patient to our tertiary-care center [22].

\section{Patient management}

10 The detailed management of patients under VA-ECMO was described previously [13, 14, 18, $1120,21]$. Briefly, pump speed was adjusted to obtain blood flow at $4-5 \mathrm{~L} / \mathrm{min}$, although at these

12 flow rates there is a risk of poor left ventricle unloading with the possibility of further left

13 ventricle-function deterioration. Intravenous unfractionated heparin was given to maintain the

14 activated partial thromboplastin time at 1.5-2-times normal. When a pulsatile arterial waveform

15 had been maintained for at least $24 \mathrm{~h}$, an ECMO-weaning trial was undertaken as described

16 elsewhere [21]. Therapeutic hypothermia $\left(32-34^{\circ} \mathrm{C}\right)$ was initiated during the first $24 \mathrm{~h}$ post-

17 cardiac arrest, according to the ILCOR guidelines [12]. Patients who could not be weaned-off

18 VA-ECMO because of persistent heart failure underwent comprehensive predictive neurological

19 work-ups, including clinical examination and electroencephalography (see online supplement).

20 When neurological prognosis was favorable, patients were bridged to a long-term left ventricle

21 assist device or cardiac transplantation, whereas patients with predicted poor neurological

22 outcomes were weaned-off VA-ECMO during withdrawal of life-sustaining therapies.

\section{Outcome variables}


1 Main outcome variables were 28-day, hospital and 12-month mortality rates. Secondary outcome

2 measures included survival to VA-ECMO weaning, number of patients bridged to a long-term

3 left ventricle assist device or cardiac transplantation, times on VA-ECMO and on mechanical

4 ventilation, duration of ICU stay, cause of mortality and multiple organ donations. Survivors to

5 hospital discharge were contacted by phone 1-year post-cardiac arrest to evaluate neurological

6 outcomes using the Cerebral Performance Category score [24].

\section{Statistical analyses}

9 Results are expressed as number (\%), continuous variables as mean (standard deviation, SD) or 10 median [interquartile range, IQR] and compared using Student's $t$-test or Wilcoxon's rank test.

11 Categorical variables were compared with $\chi^{2}$ tests. Patients' demographic, clinical and biological

12 characteristics were tested in univariable analyses for association with hospital mortality.

13 Continuous variables were transformed into categorical variables (by defining the best thresholds

14 after analyzing mortality in each corresponding-variable quartile). Thereafter, multiple logistic-

15 regression analyses using backward-stepwise variable elimination were run (with the variable-

16 exit threshold set at $P>0.10$ ). Factors achieving $P \leq 0.10$ in our univariable analyses and

17 parameters previously reported to be strongly associated with death were entered into the

18 multivariable model. All potential explanatory variables included in the multivariable analyses

19 were subjected to collinearity analysis with a correlation matrix. Variables associated with one

20 another were not included in the model. Model goodness-of-fit was assessed with the

21 determination coefficient $\left(R^{2}\right) . P<0.05$ defined statistical significance. Analyses were computed

22 with IBM SPSS Statistics v22.0 software (IBM Corp, Armonk, NY). 
1

2 In accordance with the ethical standards of our hospital's institutional review board, the

3 Committee for the Protection of Human Subjects, informed consent was not obtained for

4 demographic, physiological and hospital-outcome data analyses because this observational study

5 did not modify existing diagnostic or therapeutic strategies. However, patients and/or relatives

6 were informed about the anonymous data collection and that they could decline inclusion. The

7 National Commission for Informatics and Liberties (CNIL) approved this study (no. 1950673).

8

\section{$9 \quad$ Results}

\section{Study population}

11 Among the 954 VA-ECMO-treated patients in our ICU, 94 implanted for refractory cardiogenic

12 shock post-cardiac arrest were included (Fig. 1). Their characteristics are reported in Table 1 and

13 Table E1 (online supplement). Most patients had no or few comorbidities but were severely ill, as

14 assessed by the high simplified acute physiology score II (SAPS II) and sequential organ failure

15 assessment (SOFA) score. Median left ventricle ejection fraction was 15\% [10-20\%] (87/94

16 assessable) and aortic velocity-time integral was 7 [5-9] cm (67/94 assessable). Median cardiac

17 arrest-to-VA-ECMO-implantation interval was 7.4 [3.3-14] h and median ECMO-support

18 duration was 4 [2-6] days. VA-ECMO was implanted by our institution's Mobile Unit surgeon at

19 another hospital in $60(64 \%)$ patients, in our ICU in $17(18 \%)$, in the catheterization lab in 14

$20(15 \%)$ and by another institution's surgeon at another hospital in three (3\%) patients. Median

21 cardiac arrest-to-VA-ECMO-implantation interval was similar for patients implanted by the

22 Mobile Unit vs. the others (7.9 [3.9-18.5] vs. $5.4[3.9-11.1] \mathrm{h}$, respectively, $P=0.08)$. 


\section{Outcomes}

Respective 28-day, hospital and 12-month survival rates were 32\%, 28\% and 27\% (Table 2).

Fifty-five (59\%) patients died on VA-ECMO, 33 (35\%) were successfully weaned, four (4\%) were bridged to a left ventricle assist device and two (2\%) to heart transplantation. Causes of death were multiorgan failure for $45(65 \%)$ patients, brain death for $11(16 \%)$, post-anoxic encephalopathy for 10 (14\%) and recurrent-cardiac arrest for three (4\%; one after day 28) (Figure E1, online supplement). The 25 (27\%) 1-year survivors had good neurological outcomes (cerebral performance category 1). Among the 11 patients with confirmed brain death, five became multiple organ donors. Forty-seven (50\%) patients received an intra-aortic balloon pump (Table 2); vascular complications and outcomes were similar for patients with or without a pump (Table E1, online supplement).

(n)

\section{Comparisons between survivors and non-survivors}

The 26 survivors to hospital discharge and 68 non-survivors were comparable for age, sex, body mass index, comorbidities, cardiac arrest cause and place of occurrence, duration of resuscitation and median left ventricle ejection fraction before VA-ECMO implantation (Tables 1 and E1). Survivor's first rhythm was more frequently ventricular fibrillation, their aortic velocity-time integral pre-VA-ECMO was higher and their cardiac arrest-to-VA-ECMO-implantation intervals were longer. Non-survivors had higher SAPS II, SOFA and out-of-hospital cardiac arrest scores, higher rates of neurological and renal failures at ICU admission, higher arterial blood lactate, alanine aminotransferase and serum creatinine levels, lower prothrombin activity and urinary output on the ECMO-implantation day. According to multivariable analyses (Table 3), independent predictors of hospital mortality were international normalized ratio (INR) $>2.4$ (odds ratio (OR) 4.9; 95\% confidence interval (CI) 1.4-17.2), admission SOFA score >14 (OR 5.3; 
$195 \%$ CI 1.7-16.5) and shockable rhythm (OR 0.3; 95\% CI 0.1-0.9). The Survival After Veno-

2 arterial Extracorporeal membrane oxygenation (SAVE) score [15] was not independently

3 associated with outcome (see online supplement).

$4 \quad$ Comparable results were obtained when analyzing factors associated with 1-year

5 mortality: INR and admission SOFA score were independent predictors of 1-year mortality

6 (Tables E3 and E4 in the online supplement).

7 Figure 2 shows the Kaplan-Meyer survival-probability curves according to SOFA-score

8 quartiles, and Figures E1 and E2 for all patients and according to pre-ECMO SOFA scores

9 (online supplement). Only 10\% of patients with pre-ECMO SOFA scores >14 survived; almost

10 all deaths occurred during the first $24 \mathrm{~h}$, whereas patients with pre-ECMO SOFA scores $\leq 14 \mathrm{had}$

$1150 \%$ 1-year survival.

\section{Discussion}

14 This large cohort of patients with refractory cardiogenic shock post-cardiac arrest showed that

15 VA-ECMO was an effective rescue technique, with 27\%1-year survival; all survivors had

16 favorable neurological outcomes. When analyzing survival according to disease severity at

17 ECMO initiation, $50 \%$ of patients with admission SOFA scores $\leq 14$ survived, whereas only $10 \%$

18 with pre-ECMO multiorgan failure (i.e., SOFA scores >14) survived, raising the question of

19 futility for this population. Interestingly, most patients died early of multiorgan failure. Because

20 we included a wide variety of patients (i.e., in- or out-of-hospital cardiac arrest of various

21 causes), we analyzed a subgroup of patients with out-of-hospital cardiac arrest of coronary origin

22 and found comparable results: one-third survived at 1 year, and survival poor for the most

23 severely ill (see online supplement). 
Few data are available on the potential usefulness of circulatory support for patients in

2 cardiogenic shock after return of spontaneous circulation post-cardiac arrest; however, post-

3 cardiac arrest myocardial dysfunction contributes to the low survival rate after in- and out-of-

4 hospital cardiac arrests. In a retrospective study on 205 in-hospital and out-of-hospital cardiac

5 arrest patients, 33\% died of cardiovascular failure and multiorgan failure [25]. In another out-of-

6 hospital cardiac arrest cohort, 73/165 (44\%) patients suffered from hemodynamic instability with

7 significant left ventricle dysfunction (median left ventricle ejection fraction, $32 \%$ ) and $8 \%$ of the

8 total (19.2\% of the 73 with hemodynamic instability) died of early shock [26]. In a more recent

9 study on 1152 cardiac arrests, 789 (68\%) developed post-cardiac arrest shock, with 73\%

10 mortality; the etiology of shock was not reported but it is highly probable that some patients had

11 pure cardiogenic shock, some pure vasoplegia and others both [27]. Some data indicate that this

12 phenomenon is responsive to therapy and reversible [26, 28].

However, myocardial dysfunction persists in some patients and may lead to cardiogenic

14 shock refractory to conventional medical therapies (fluid resuscitation and inotropic drugs).

15 Mechanical circulatory support could be considered at that time until myocardial recovery or to

16 bridge patients with predicted favorable neurological outcomes toward long-term assist device or

17 heart transplantation. Intra-aortic balloon pumps have been evaluated in the setting of cardiogenic

18 shock, with $45 \%$ of patients post-cardiac arrest resuscitation, but results were disappointing [29].

19 The Impella percutaneous left ventricle assist device has also been proposed to treat refractory

20 cardiogenic shock post-cardiac arrest but with limited data [30, 31]. VA-ECMO has been

21 extensively investigated for e-CPR for refractory cardiac arrest but with discordant findings [18-

22 20].

However, no studies have specifically investigated the possible VA-ECMO usefulness

24 and risk factors associated with mortality in patients with refractory cardiogenic shock post- 
cardiac arrest, as most of the studies that focused on VA-ECMO for refractory cardiogenic shock mixed patients with or without cardiac arrest and even refractory cardiac arrest [30, 31]. In the most recent [32], among 138 patients implanted with VA-ECMO for acute myocardial infarctionrelated cardiogenic shock in two French ECMO centers, 79 (57\%) suffered cardiac arrest preVA-ECMO implantation, including 19 (14\%) with implantation during CPR; 65 (47\%) survived to discharge. Factors independently associated with mortality were age $>60$ years, female sex, body mass index $>25 \mathrm{~kg} / \mathrm{m}^{2}$, Glasgow Coma Score $<6$, serum creatinine $>150 \mu \mathrm{mol} / \mathrm{L}$, elevated serum arterial lactate and prothrombin activity $<50 \%$. In the Extracorporeal Life Support Organization cohort of 3846 refractory cardiogenic shock patients, 1240 (32\%) had experienced pre-ECMO cardiac arrest; 456 (37\%) of them survived and were discharged [15]. Again, longterm follow-up and neurological outcomes were not available. According to their multivariable analysis, cardiac arrest was independently associated with poorer survival. Although our cohort's survival to discharge seems to be slightly lower than that of cardiogenic shock patients without prior cardiac arrest, we reported long-term survival and 1-year neurological outcomes, information often lacking in earlier publications. Moreover, we were able to identify factors associated with mortality in this specific population, whereas other studies mixed patients put on ECMO for cardiogenic shock, post-cardiac arrest cardiogenic shock or refractory cardiac arrest. Our findings support VA-ECMO feasibility for extremely severe patients with refractory cardiogenic shock post-cardiac arrest, with 27\% 1-year survival and good neurological outcomes, comparable to those of patients not requiring ECMO implantation [12]. Patient selection (reflected partly by their low mean age) may have played a role in this outcome. Moreover, our 1-year survivors' good neurological outcomes are partly explained by selective pressure: those with severe neurological injury died early (12\% had initial poor neurological outcome prediction and care was withdrawn) and hospital survivors with severe brain injury 
usually die early after hospital discharge. However, patients with severe multiorgan failure have very poor prognoses and, in our experience, survival of patients with pre-ECMO ICU-admission SOFA scores $>14$ was very low, raising the question of futility. This crucial decision might be addressed by survival-predictive models, which aim to help clinicians select patients who are more likely to survive on ECMO [15, 32]. For acute myocardial infarction, the ENCOURAGE score, which integrates extracardiac organ failure, showed good performance to predict survival in this context [32]. In our population, ENCOURAGE and SAVE scores seem less accurate than the SOFA score for our patients, since multivariable analyses retained only the SOFA score as being associated with hospital and 1-year mortality. This lack of association is probably explained by almost all patients being in the high-risk classes of both scores, with low survival probability.

Notably, ECMO is not an obstacle to care withdrawal: seven of our patients could not be weaned-off ECMO and had dismal neurological prognoses. Their ECMO was removed during care withdrawal. Strikingly, cardiac arrest variables (witnessed status, bystander CPR, low-flow and no-flow times...) and other traditional post-arrest predictors (SAPS II score, blood lactate level, acute renal failure or out-of-hospital cardiac arrest score) were not independently associated with mortality. We have no clear explanation for these findings, but it is highly possible that due to our population's specifics, patient survival mostly reflected shock intensity (and the related organ failures) rather than "traditional" cardiac arrest parameters or scores. Although not statistically significant herein, cardiac-arrest-to-ECMO-start interval could also be an important factor to consider for patient selection, with longer times being associated with more severe multiorgan failure.

This study has several limitations. First, it is a retrospective, monocenter-cohort analysis of information collected prospectively. Second, included patients might not reflect the global 
1 cardiogenic shock population post-cardiac arrest resuscitation, the cardiogenic shock post-cardiac

2 arrest frequency or the number of refractory shock patients requiring VA-ECMO. Indeed, most

3 patients were admitted to other hospitals' ICUs and referred to us for VA-ECMO assistance.

4 Moribund, elderly or highly comorbid patients may not have been considered for ECMO or may

5 have been rejected because of obvious futility. Third, despite our ICU's strict ECMO-

6 implantation criteria, we are not sure that all criteria were fulfilled by all the patients included.

7 Indeed, because most of our patients $(63 / 94,67 \%)$ were put on ECMO in another hospital, data

8 on pre-ECMO echocardiography, blood pressure and catecholamine use were not always entered

9 in the medical charts, meaning all these criteria could not be verified. However, because our

10 policy is to implant VA-ECMO only in patients with cardiogenic shock (and not those with

11 vasoplegia and hyperkinetic state), it is highly probable that all patients had severe cardiogenic

12 shock with hypotension, tissue hypoxia, low cardiac output and high inotrope doses. Moreover,

13 post-ECMO echocardiography showed left ventricle ejection fraction $<25 \%$ with aortic velocity-

14 time integral $<8 \mathrm{~cm}$ in all patients. Fourth, we mixed patients with different cardiac arrest causes.

15 However, when the analysis was restricted to patients with out-of-hospital cardiac arrest due to

16 acute coronary syndrome, the same results were obtained. Fifth, circulatory failure in our cohort

17 reflected left ventricular dysfunction (i.e. cardiogenic shock). Thus, our results cannot be

18 generalized to patients with refractory post-cardiac arrest syndrome and preserved (or moderately

19 decreased) cardiac output and vasoplegia. Lastly, we would have liked to have a control group

20 with cardiogenic shock post-cardiac arrest for comparison; however, the severity of our patients'

21 cardiogenic shock made it impossible to match our cases with controls.

\section{CONCLUSION}

24 In this retrospective cohort of severely ill patients who received VA-ECMO for refractory 
1 cardiogenic shock post-cardiac arrest resuscitation, 27\% were alive at 1 year with good

2 neurological outcomes. VA-ECMO might be considered a rescue therapy for patients with

3 refractory cardiogenic shock post-cardiac arrest. Patients with multiorgan failure (defined as

4 SOFA score >14), high INR (>2.4) and no shockable rhythm at the time of implantation had

5 poorer outcomes, raising the question of the futility of this technique for such patients.

6

7

8

9

10 
2 1. Donnino MW, Miller JC, Bivens M et al (2012) A pilot study examining the severity and outcome of the post-cardiac arrest syndrome: a comparative analysis of two geographically distinct hospitals. Circulation 126:1478-1483. doi:

\subsection{1/CIRCULATIONAHA.111.067256}

2. Adrie C, Cariou A, Mourvillier B et al (2006) Predicting survival with good neurological recovery at hospital admission after successful resuscitation of out-of-hospital cardiac arrest: the OHCA score. Eur Heart J 27:2840-2845. doi: 10.1093/eurheartj/ehl335

3. Girotra S, Nallamothu BK, Spertus JA et al (2012) Trends in survival after in-hospital cardiac arrest. N Engl J Med 367:1912-1920. doi: 10.1056/NEJMoa1109148

4. Eisenberg MS, Mengert TJ (2001) Cardiac resuscitation. N Engl J Med 344:1304-1313. doi: 10.1056/NEJM200104263441707

5. Bunch TJ, White RD, Gersh BJ et al (2003) Long-term outcomes of out-of-hospital cardiac arrest after successful early defibrillation. N Engl J Med 348:2626-2633. doi: 10.1056/NEJMoa023053

6. Bernard SA, Gray TW, Buist MD et al (2002) Treatment of comatose survivors of out-ofhospital cardiac arrest with induced hypothermia. N Engl J Med 346:557-563. doi: 10.1056/NEJMoa003289

7. Hypothermia after Cardiac Arrest Study Group (2002) Mild therapeutic hypothermia to improve the neurologic outcome after cardiac arrest. N Engl J Med 346:549-556. doi: 10.1056/NEJMoa012689

8. Bougouin W, Lamhaut L, Marijon E et al (2014) Characteristics and prognosis of sudden cardiac death in greater Paris. Intensive Care Med 40:846-854. doi: 10.1007/s00134-014$3270-3$ 
19 . Citerio G, Bakker J, Bassetti M et al (2015) Year in review in Intensive Care Medicine

2014: I. Cardiac dysfunction and cardiac arrest, ultrasound, neurocritical care, ICU-acquired weakness, nutrition, acute kidney injury, and miscellaneous. Intensive Care Med 41:179_ 191. doi: 10.1007/s00134-015-3665-9

10. Paul M, Bougouin W, Geri G et al (2016) Delayed awakening after cardiac arrest: prevalence and risk factors in the Parisian registry. Intensive Care Med 42:1128-1136. doi: $10.1007 / \mathrm{s} 00134-016-4349-9$

11. Mongardon N, Dumas F, Ricome S et al (2011) Postcardiac arrest syndrome: from immediate resuscitation to long-term outcome. Ann Intensive Care 1:45. doi: 10.1186/2110$5820-1-45$

12. Nolan JP, Neumar RW, Adrie C et al (2008) Post-cardiac arrest syndrome: epidemiology, pathophysiology, treatment, and prognostication. A Scientific Statement from the International Liaison Committee on Resuscitation; the American Heart Association Emergency Cardiovascular Care Committee; the Council on Cardiovascular Surgery and Anesthesia; the Council on Cardiopulmonary, Perioperative, and Critical Care; the Council on Clinical Cardiology; the Council on Stroke. Resuscitation 79:350-379. doi: 10.1016/j.resuscitation.2008.09.017

13. Perner A, Citerio G, Bakker J et al (2015) Year in review in Intensive Care Medicine 2014: II. ARDS, airway management, ventilation, adjuvants in sepsis, hepatic failure, symptoms assessment and management, palliative care and support for families, prognostication, organ donation, outcome, organisation and research methodology. Intensive Care Med 41:389_ 401. doi: 10.1007/s00134-015-3707-3

14. Timsit J-F, Perner A, Bakker J et al (2015) Year in review in Intensive Care Medicine 2014: III. Severe infections, septic shock, healthcare-associated infections, highly resistant 
bacteria, invasive fungal infections, severe viral infections, Ebola virus disease and paediatrics. Intensive Care Med 41:575-588. doi: 10.1007/s00134-015-3755-8

15. Schmidt M, Burrell A, Roberts L et al (2015) Predicting survival after ECMO for refractory cardiogenic shock: the Survival After Veno-arterial-ECMO (SAVE)-score. Eur Heart J 36:2246-2256. doi: 10.1093/eurheartj/ehv194

16. Mirabel M, Luyt C-E, Leprince P et al (2011) Outcomes, long-term quality of life, and psychologic assessment of fulminant myocarditis patients rescued by mechanical circulatory support. Crit Care Med 39:1029-1035. doi: 10.1097/CCM.0b013e31820ead45

17. Combes A, Leprince P, Luyt C-E et al (2008) Outcomes and long-term quality-of-life of patients supported by extracorporeal membrane oxygenation for refractory cardiogenic shock. Crit Care Med 36:1404-1411. doi: 10.1097/CCM.0b013e31816f7cf7

18. Le Guen M, Nicolas-Robin A, Carreira S et al (2011) Extracorporeal life support following out-of-hospital refractory cardiac arrest. Crit Care 15:R29. doi: 10.1186/cc9976

19. Abrams D, Combes A, Brodie D (2014) What's new in extracorporeal membrane oxygenation for cardiac failure and cardiac arrest in adults? Intensive Care Med 40:609612. doi: 10.1007/s00134-014-3212-0

20. Xie A, Phan K, Tsai Y-C et al (2015) Venoarterial extracorporeal membrane oxygenation for cardiogenic shock and cardiac arrest: a meta-analysis. J Cardiothorac Vasc Anesth 29:637-645. doi: 10.1053/j.jvca.2014.09.005

21. Aissaoui N, Luyt C-E, Leprince P et al (2011) Predictors of successful extracorporeal membrane oxygenation (ECMO) weaning after assistance for refractory cardiogenic shock. Intensive Care Med 37:1738-1745. doi: 10.1007/s00134-011-2358-2

22. Beurtheret S, Mordant P, Paoletti X et al (2013) Emergency circulatory support in refractory cardiogenic shock patients in remote institutions: a pilot study (the cardiac-RESCUE 
program). Eur Heart J 34:112-120. doi: 10.1093/eurheartj/ehs081

23. Luyt C-E, Bréchot N, Demondion P et al (2016) Brain injury during venovenous extracorporeal membrane oxygenation. Intensive Care Med 42:897-907. doi: $10.1007 / \mathrm{s} 00134-016-4318-3$

24. Rittenberger JC, Raina K, Holm MB et al (2011) Association between Cerebral Performance Category, Modified Rankin Scale, and discharge disposition after cardiac arrest. Resuscitation 82:1036-1040. doi: 10.1016/j.resuscitation.2011.03.034

25. Laver S, Farrow C, Turner D, Nolan J (2004) Mode of death after admission to an intensive care unit following cardiac arrest. Intensive Care Med 30:2126-2128. doi: 10.1007/s00134$004-2425-z$

26. Laurent I, Monchi M, Chiche J-D et al (2002) Reversible myocardial dysfunction in survivors of out-of-hospital cardiac arrest. J Am Coll Cardiol 40:2110-2116.

27. Lemiale V, Dumas F, Mongardon N et al (2013) Intensive care unit mortality after cardiac arrest: the relative contribution of shock and brain injury in a large cohort. Intensive Care Med 39:1972-1980. doi: 10.1007/s00134-013-3043-4

28. Ruiz-Bailén M, Aguayo de Hoyos E, Ruiz-Navarro S et al (2005) Reversible myocardial dysfunction after cardiopulmonary resuscitation. Resuscitation 66:175-181. doi: 10.1016/j.resuscitation.2005.01.012

29. Thiele H, Zeymer U, Neumann F-J et al (2012) Intraaortic balloon support for myocardial infarction with cardiogenic shock. N Engl J Med 367:1287-1296. doi: 10.1056/NEJMoa1208410

30. Manzo-Silberman S, Fichet J, Mathonnet A et al (2013) Percutaneous left ventricular assistance in post cardiac arrest shock: comparison of intra aortic blood pump and Impella Recover LP2.5. Resuscitation 84:609-615. doi: 10.1016/j.resuscitation.2012.10.001 
1 31. Mukku VK, Cai Q, Gilani S et al (2012) Use of Impella ventricular assist device in patients with severe coronary artery disease presenting with cardiac arrest. Int J Angiol 21:163-166. doi: $10.1055 / \mathrm{s}-0032-1324736$

4 32. Muller G, Flecher E, Lebreton G et al (2016) The ENCOURAGE mortality risk score and analysis of long-term outcomes after VA-ECMO for acute myocardial infarction with cardiogenic shock. Intensive Care Med 42:370-378. doi: 10.1007/s00134-016-4223-9 
1 Table 1. Main characteristics of all venoarterial extracorporeal membrane oxygenation-treated

2 patients at ICU admission and comparisons between hospital survivors and non-survivors

\begin{tabular}{|c|c|c|c|c|}
\hline Characteristic & $\begin{array}{l}\text { Entire Cohort } \\
(n=94)\end{array}$ & $\begin{array}{l}\text { Survivors } \\
(n=26)\end{array}$ & $\begin{array}{l}\text { Non-Survivors } \\
(n=68)\end{array}$ & $P$ \\
\hline Age (y) & $50.8 \pm 11.5$ & $49.96 \pm 10$ & $51.1 \pm 12.1$ & 0.6 \\
\hline Male sex & $71(76)$ & $20(76.9)$ & $51(75)$ & 0.8 \\
\hline Body mass index $\left(\mathrm{kg} / \mathrm{m}^{2}\right)$ & $26.2[23.4-29.3]$ & $25.8[23.7-28.1]$ & $26.1[23.4-29.4]$ & 0.9 \\
\hline \multicolumn{5}{|l|}{ McCabe \& Jackson score for } \\
\hline comorbidity & $1[0-2]$ & $0.5[0-2]$ & $1[0-2]$ & 0.7 \\
\hline SAPS II & $82[77-88]$ & $77[67.5-83]$ & 84 [79-89] & 0.002 \\
\hline SOFA score & $13[15-17]$ & $13[12-14]$ & $16[14-18]$ & $<0.0001$ \\
\hline \multicolumn{5}{|l|}{ Organ failure ${ }^{a}$} \\
\hline Cardiovascular system & $94(100)$ & $26(100)$ & $68(100)$ & - \\
\hline Lung & $94(100)$ & $26(100)$ & $68(100)$ & - \\
\hline Brain & $91(97)$ & $24(92.3)$ & $67(98.5)$ & 0.01 \\
\hline Kidney & $48(51)$ & $5(19.2)$ & $43(63.2)$ & $<0.0001$ \\
\hline Hematological & $6(6)$ & $1(3.8)$ & $5(7.4)$ & 0.5 \\
\hline Liver & $2(2)$ & 0 & $2(2.9)$ & 0.3 \\
\hline Out-of-hospital cardiac arrest score [2] & $41.3[30.8-50.9]$ & $32.4[24.7-42.6]$ & $43.9[33.9-51.9]$ & 0.001 \\
\hline \multicolumn{5}{|l|}{ Etiology of cardiac arrest } \\
\hline Myocardial infarction & $66(70)$ & $19(73.1)$ & $47(69.1)$ & 0.7 \\
\hline \multicolumn{5}{|l|}{ Acute decompensation of chronic } \\
\hline cardiomyopathy & $8(9)$ & $3(11.5)$ & $5(7.4)$ & 0.5 \\
\hline
\end{tabular}




\begin{tabular}{|c|c|c|c|c|}
\hline Pulmonary embolism & $4(4)$ & $2(7.7)$ & $2(2.9)$ & 0.3 \\
\hline Drug intoxication & $3(3)$ & 0 & $3(4.4)$ & 0.2 \\
\hline Anaphylactic shock & $3(3)$ & $2(7)$ & $1(1.5)$ & 0.1 \\
\hline Miscellaneous $^{\mathrm{b}}$ & $10(11)$ & $0(0)$ & $10(14.7)$ & 0.04 \\
\hline Witnessed cardiac arrest & $88(94)$ & $25(96)$ & $63(93)$ & 0.5 \\
\hline Attempted defibrillation & $56(60)$ & $21(80.8)$ & $35(51.5)$ & 0.01 \\
\hline Bystander-attempted CPR & $76(81)$ & $21(80.8)$ & $55(80.9)$ & 0.9 \\
\hline No flow (min) & $0[0-5]$ & $0[0-3.5]$ & $0[0-5]$ & 0.9 \\
\hline Low flow (min) & $30[15-43]$ & $27.5[10-40]$ & $30[16-45]$ & 0.3 \\
\hline Out-of-hospital cardiac arrest & $78(83)$ & $22(85)$ & $56(82)$ & 0.7 \\
\hline Shockable rhythm & $56(60)$ & $21(81)$ & $35(52)$ & 0.02 \\
\hline Cardiac arrest-to-VA-ECMO interval (h) & $7.4[3.3-14]$ & $10.7[4.1-18.8]$ & $6.3[3-13]$ & 0.07 \\
\hline ECMO implanted by mobile team & $60(64)$ & $15(58)$ & $45(66)$ & 0.5 \\
\hline Therapeutic hypothermia & $75(80)$ & $19(73)$ & $56(82)$ & 0.3 \\
\hline \multicolumn{5}{|l|}{ Pre-ECMO echocardiographic findings } \\
\hline Left ventricular ejection fraction ${ }^{\mathrm{c}}(\%)$ & $15[10-20]$ & $15[10-20]$ & $15[10-20]$ & 0.3 \\
\hline Aortic velocity-time integral ${ }^{\mathrm{d}}(\mathrm{cm})$ & $7[5-9]$ & $8[6-10]$ & $6[5-8]$ & 0.06 \\
\hline SAVE-score risk class [15] & & & & 0.007 \\
\hline I & 0 & 0 & 0 & \\
\hline II & 0 & 0 & 0 & \\
\hline III & $6(6)$ & $1(4)$ & $5(7)$ & \\
\hline IV & $28(30)$ & $14(54)$ & $14(21)$ & \\
\hline $\mathrm{V}$ & $60(64)$ & $11(42)$ & $49(72)$ & \\
\hline
\end{tabular}


Abbreviations: SAPS simplified acute physiology score, SOFA sequential organ failure assessment, $C P R$ cardiopulmonary resuscitation, $V A-E C M O$ venoarterial extracorporeal membrane oxygenation, SAVE Survival after VA-ECMO

Continuous variables are expressed as mean $\pm \mathrm{SD}$ or median [IQR] and compared using Student's $t$-test or Wilcoxon's rank test. Categorical variables are expressed as $n(\%)$ and were compared with $\chi^{2}$ tests.

${ }^{\text {a }}$ Deemed present when the corresponding SOFA score was $>2$.

${ }^{\mathrm{b}}$ Miscellaneous causes of cardiac arrest: hypoxic cardiac arrest and/or potassium disorders: 2 each; and 1 each: near drowning, myocarditis, subarachnoid hemorrhage, amniotic fluid embolism, postpartum hemorrhage or idiopathic cardiac arrhythmia.

${ }^{\mathrm{c}}$ Available for 87 patients (27 survivors and 59 non-survivors).

${ }^{\mathrm{d}}$ Available for 67 patients (25 survivors and 42 non-survivors). 
ICME-D16-00906 R5

1 Table 2. Outcome measures for all $94 \mathrm{VA}-\mathrm{ECMO}-$ treated patients

\begin{tabular}{|c|c|}
\hline Outcome measure & Value \\
\hline VA-ECMO duration (days) & $4[2-6]$ \\
\hline Intensive care unit length of stay (days) & $4[1-13]$ \\
\hline Mechanical ventilation duration (days) & $4[2-11]$ \\
\hline \multicolumn{2}{|l|}{ ECMO complications } \\
\hline Limb ischemia & $14(15)$ \\
\hline Fasciotomy & $4(4)$ \\
\hline Amputation & $1(1)$ \\
\hline Bleeding & $24(26)$ \\
\hline Infection & $17(18)$ \\
\hline \multicolumn{2}{|l|}{ Mechanical support during ECMO } \\
\hline Intra-aortic balloon pump & $47(50)$ \\
\hline Impella $^{\circledR}$ & $2(2)$ \\
\hline \multicolumn{2}{|l|}{ VA-ECMO weaning } \\
\hline Yes & $33(35)$ \\
\hline No & $61(65)$ \\
\hline Died on ECMO & $55(59)$ \\
\hline Left ventricular assist device & $4(4)$ \\
\hline Heart transplantation & $2(2)$ \\
\hline 28-Day survival & $30(32)$ \\
\hline Hospital survival & $26(28)$ \\
\hline 12-Month survival & $25(27)$ \\
\hline
\end{tabular}


Cause of death $(n=69)$

Multiorgan failure

Brain death

$11(16)$

Post-anoxic encephalopathy

$10(14)$

Cardiac arrest recurrence

Multiple organ donation ${ }^{\mathrm{a}}$

$5(5)$

1 Abbreviations: $V A-E C M O$ venoarterial extracorporeal membrane oxygenation

2 Continuous variables are expressed as median [IQR] and categorical variables as $n(\%)$.

$3{ }^{\text {a }}$ Reasons for refusing organ donation: 3 with persistent multiorgan failure, and 1 each with

4 family refusal, pregnancy or liver transplantation. 
1 Table 3. Univariable and multivariable analyses of factors associated with hospital mortality

\begin{tabular}{|c|c|c|c|c|}
\hline Factor & $\begin{array}{l}\text { Univariable } \\
\text { analysis }\end{array}$ & $P$ & $\begin{array}{l}\text { Multivariable } \\
\text { analysis }\end{array}$ & $P$ \\
\hline & OR $[95 \% \mathrm{CI}]$ & & OR $[95 \% \mathrm{CI}]$ & \\
\hline Arterial lactate $>11.5, \mathrm{mmol} / \mathrm{L}$ & $4.7[1.7-12.7]$ & 0.003 & & \\
\hline International normalized ratio $>2.4$ & $7.8[2.4-25.3]$ & 0.0006 & $4.9[1.4-17.2]$ & 0.01 \\
\hline Renal failure at ICU admission ${ }^{a}$ & $7.2[2.4-21.5]$ & 0.0004 & & \\
\hline Pre-VA-ECMO SOFA score $>14$ & $7.5[2.6-21.3]$ & 0.0002 & $5.3[1.7-16.5]$ & 0.004 \\
\hline SAPS II > 82 & $3.4[1.3-9.3]$ & 0.01 & & \\
\hline Shockable rhythm & $0.3[0.1-0.7]$ & 0.01 & $0.3[0.1-0.9]$ & 0.04 \\
\hline
\end{tabular}

Abbreviations: INR international normalized ratio, VA-ECMO venoarterial-extracorporeal membrane oxygenation, SOFA sequential organ failure assessment, SAPS simplified acute physiology score

${ }^{a}$ Defined as a renal SOFA score of 3 or 4.

The following variables were included in the multivariable model: arterial lactate $>11.5 \mathrm{mmol} / \mathrm{L}$, INR $>2.4$, pre-VA-ECMO SOFA score $>14$ and shockable rhythm. SAPS II and renal failure at ICU admission were not included in the final model because they were strongly associated with the SOFA score. Model $R^{2}=0.26$. 
ICME-D16-00906 R5

\section{Figure legends}

2 Fig. 1 Flow-chart of the study

3 Fig. 2 Kaplan-Meier probability of survival curves according to Sequential Organ Failure

4 Assessment score quartile at admission

5 Fig. 3 Cause of death (neurological injury or multiorgan failure) according to the time between

6 extracorporeal membrane oxygenation start and death 
$1 \quad$ Fig 1

954 Venoarterial-extracorporeal membrane oxygenation-treated patients

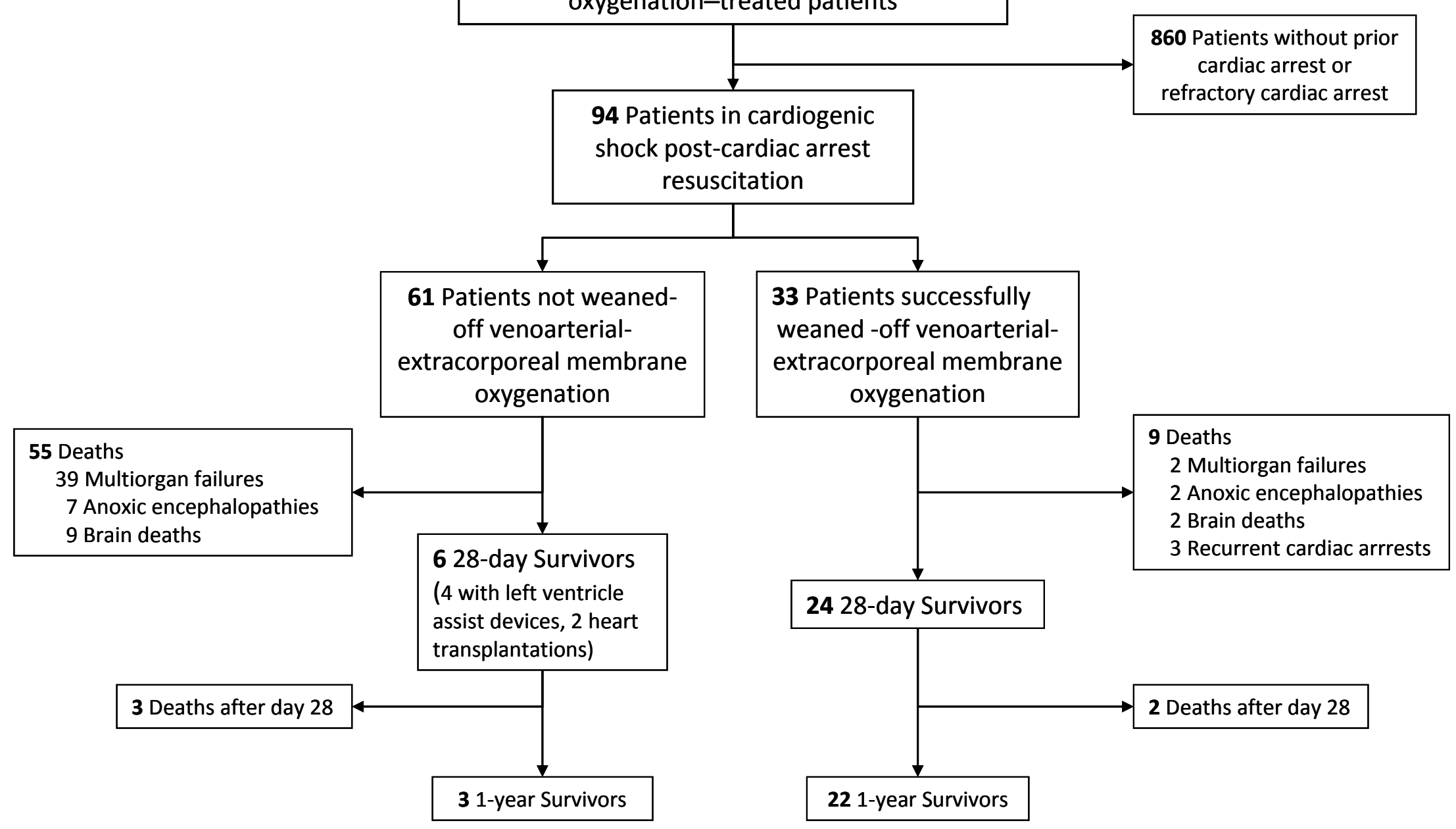


$1 \quad$ Fig 2

2

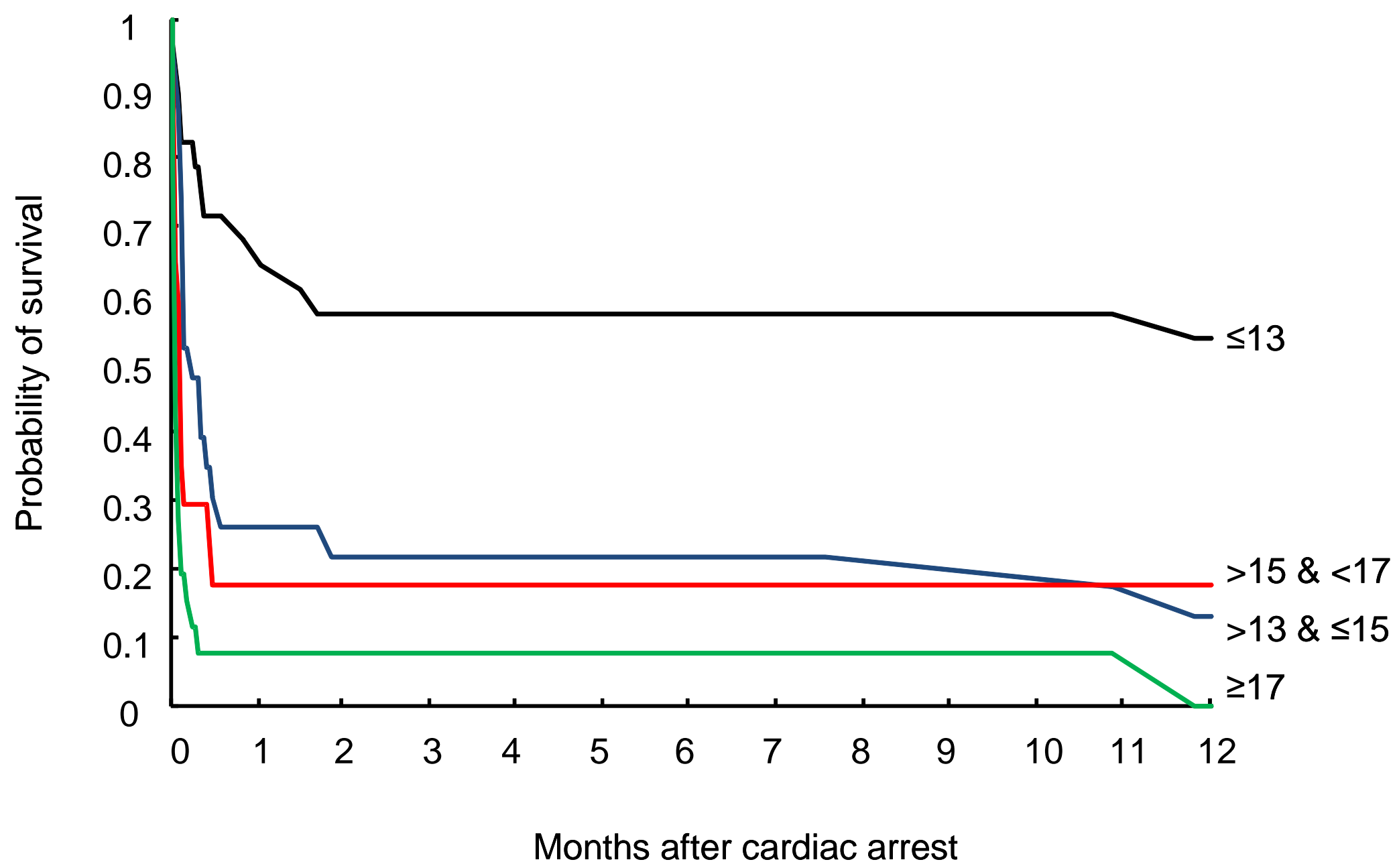


$1 \quad$ Fig 3

2

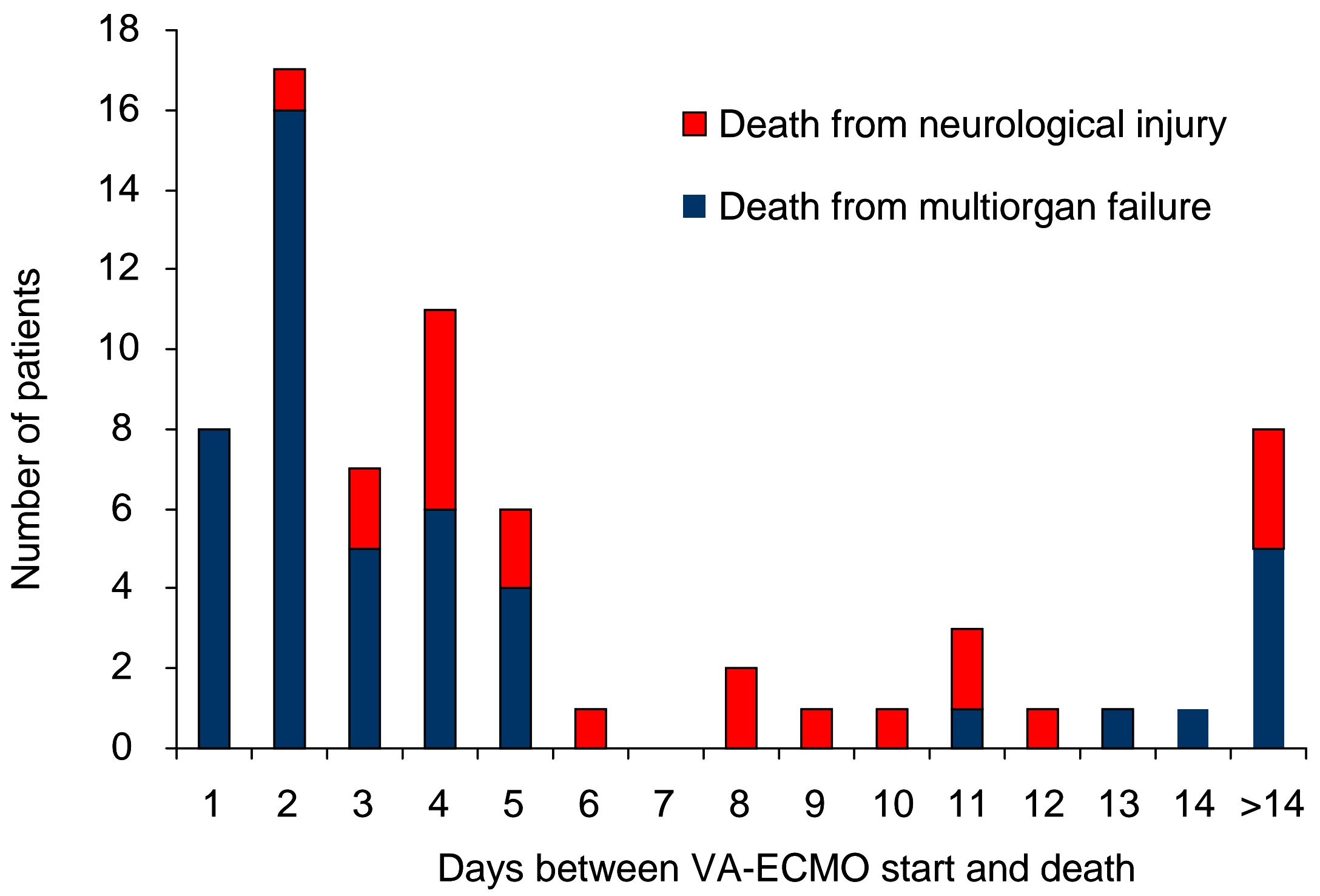

